\title{
UNIVERSITYOF
}

FORWARD

THINKING

WESTMINSTER用

WestminsterResearch

http://www.westminster.ac.uk/westminsterresearch

\section{Dual-band WLAN Antenna Array with Integrated Bandpass Filters for Harmonic Suppression}

Ahmad, W.

This is a copy of the author's accepted version of a paper subsequently published in the proceedings of AP-S International Symposium on Antennas and Propagation (APS2015), Vancouver, British Columbia, Canada, 19 to 24 Jul 2015.

It is available online at:

https://dx.doi.org/10.1109/APS.2015.7304696

(C) 2015 IEEE . Personal use of this material is permitted. Permission from IEEE must be obtained for all other uses, in any current or future media, including reprinting/republishing this material for advertising or promotional purposes, creating new collective works, for resale or redistribution to servers or lists, or reuse of any copyrighted component of this work in other works.

The WestminsterResearch online digital archive at the University of Westminster aims to make the research output of the University available to a wider audience. Copyright and Moral Rights remain with the authors and/or copyright owners.

Whilst further distribution of specific materials from within this archive is forbidden, you may freely distribute the URL of WestminsterResearch: ((http://westminsterresearch.wmin.ac.uk/)).

In case of abuse or copyright appearing without permission e-mail repository@westminster.ac.uk 


\title{
Dual-band WLAN Antenna Array with Integrated Bandpass Filters for Harmonic Suppression
}

\author{
Waqas Ahmad and Djuradj Budimir \\ Wireless Communications Research Group \\ University of Westminster \\ London, W1W 6UW, UK \\ waqas.ahmad@my.westminster.ac.uk and d.budimir@westminster.ac.uk
}

\begin{abstract}
This paper presents the design and results of a dualband antenna array integrated with bandpass filters. The array has a 1x2 configuration. The two bands of the array correspond to the two WLAN bands of $2.4 \mathrm{GHz}$ and $5.8 \mathrm{GHz}$. Other than the two main bands, the standalone array exhibits spurious harmonics at various other frequencies. For the suppression of these harmonics, the array is integrated with two bandpass filters, centered at $2.4 \mathrm{GHz}$ and $5.8 \mathrm{GHz}$. The filtering array was simulated and fabricated. Measured results show dual-bands at $2.4 \mathrm{GHz}$ and $5.8 \mathrm{GHz}$ at a return loss of more than $30 \mathrm{~dB}$ and also a successful full suppression of the spurious harmonics.
\end{abstract}

\section{INTRODUCTION}

The WLAN operates at $2.4 \mathrm{GHz}$ and $5.8 \mathrm{GHz}$ as defined by the IEEE $802.11 \mathrm{a} / \mathrm{b} / \mathrm{g} / \mathrm{n} / \mathrm{ac}$ standards [1]. Currently, the 2.4 $\mathrm{GHz}$ and $5.8 \mathrm{GHz}$ point-to-point antenna arrays are mounted separately with discrete ports [2]. It is difficult to achieve a broadband planar antenna array with stable directional radiation patterns from $2.0-6.0 \mathrm{GHz}$, as gain is proportional to the radiation aperture [2]. Hence, a dual-band array structure is preferred due to its simple system configuration and cost minimization. Although similar work has been proposed in [2] and [3], but is disadvantageous with respect to quite a number of factors; such as, larger $2 \times 2$ array structures, single-band operation, final response not being sufficiently sharp and most importantly spurious harmonics not being fully rejected. Similarly, [4] and [5] are unfavorable as well since the filters employed are of $3^{\text {rd }}$ and $4^{\text {th }}$ orders, and again the spurious harmonics have not been fully rejected. In this presented work, a dual-band $1 \times 2$ antenna array with $2^{\text {nd }}$ order integrated filters has been designed. Also a full suppression of the spurious harmonics has been satisfactorily achieved. In section II, the design of the proposed structure is detailed. Section III and IV present the results and conclusions of the work respectively.

\section{DESIGN OF PROPOSED ARRAYS}

The proposed array is illustrated in Fig. 1. It consists of two antenna patches, designed at resonant frequencies of $2.4 \mathrm{GHz}$ and $5.8 \mathrm{GHz}$. The two patches are joined to $50 \Omega$ transmission lines via $\lambda \mathrm{g} / 4$ long transmission lines of impedance $76.71 \Omega$; where $\lambda \mathrm{g} / 4$ is the guided wavelength at each patch's respective resonant frequency. The whole structure is fed by means of a single $50 \Omega$ port. The power from this port is split in to two branches through a transmission line of an impedance $76.71 \Omega$. The length of this power-splitting transmission line is dependent on the spacing between the two patch antennas. The two patch antennas are spaced at a distance of $0.33 \lambda \mathrm{g}$ in order to minimize mutual coupling; where $\lambda g$ is the guided wavelength at $2.4 \mathrm{GHz}$. The two designed patch antennas are then connected to the two ends of the power-splitting line via pseudo-interdigital bandpass filters of $2^{\text {nd }}$ order each. The folded interdigital fingers of each filter are $\lambda \mathrm{g} / 2$ long, where $\lambda g / 2$ is the guided wavelength at the center frequency of each filter which is the respective resonant frequency of the patch it is connected to. The power-splitting transmission line acts as a feedline for both filters. When the $50 \Omega$ port of the resulting structure is excited, current flows in and then gets divided in to the two branches. Since the two branches are feedlines for the two filters, the current then flows in to the two filters through coupling. Each filter then lets pass through only its respective frequency, while rejecting all others. Lastly, the two patch antennas radiate at their particular resonant frequencies, which are the same frequencies passed out by the two bandpass filters.

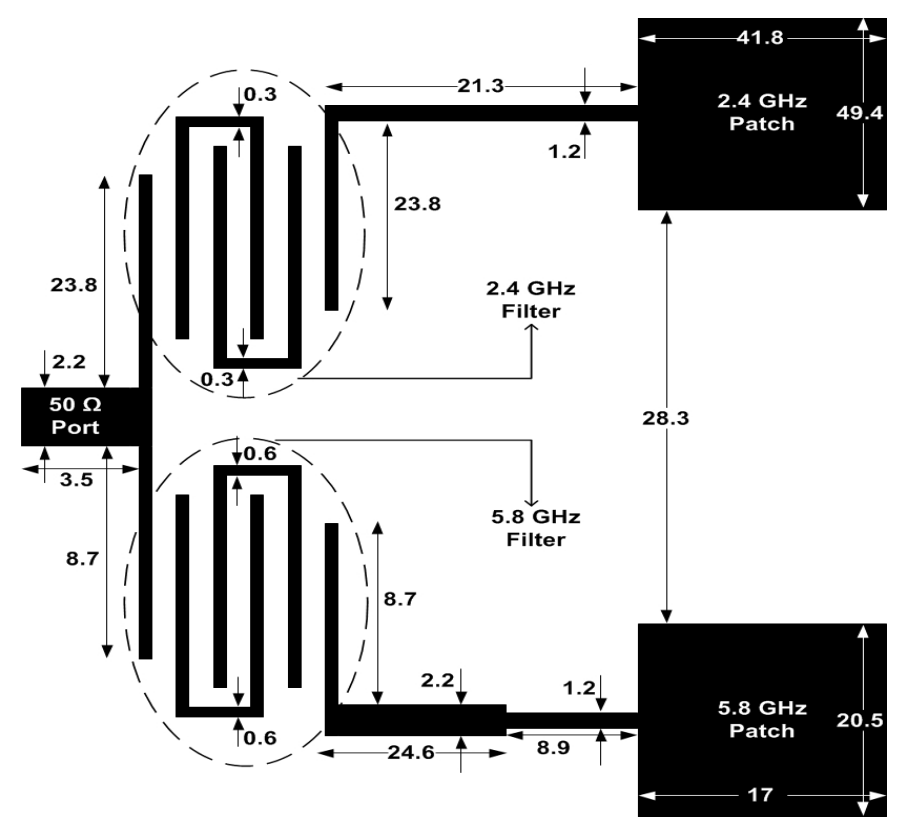

Fig 1. Geometry (in $\mathrm{mm}$ ) of array with integrated filters. 


\section{RESULTS}

A standalone array is designed on a $0.79 \mathrm{~mm}$ thick Rogers RT5880 substrate of a permittivity $\varepsilon_{\mathrm{r}}=2.2$ and loss tangent $\tan \delta=0.0009$. Simulations are done using the software emSonnet. The S-parameters of the standalone array have been presented in Fig. 2. The bands at $2.4 \mathrm{GHz}$ and $5.8 \mathrm{GHz}$ are at a return loss of almost $30 \mathrm{~dB}$ each. As also seen, other than the resonant frequencies, spurious harmonics are present at various other frequencies. These spurious harmonics interfere with the main signals and cause distortion as well as loss of sensitivity in the main signals. The simulated S-parameters of the standalone bandpass filters presented in Fig. 3 show the filters centered at $2.4 \mathrm{GHz}$ and $5.8 \mathrm{GHz}$. Results also show the filters' passband to be $2.08-2.69 \mathrm{GHz}$ and $5.51-6.11 \mathrm{GHz}$ and hence have fractional bandwidths of $25.4 \%$ and $10.4 \%$ respectively. The insertion loss is about $0.1 \mathrm{~dB}$ in the both passbands. Transmission zeroes appear at frequencies below and above the passbands of both filters. These improve near-bandwidth rejection. The return loss is more than $13 \mathrm{~dB}$ for most of the passband bandwidth in both filters. The simulation results of the filtering array are shown in Fig. 4. The proposed structure exhibits dual-band fundamental resonant frequencies and a major suppression of the spurious harmonics has been achieved, as desired. However, the pick at $4.5 \mathrm{GHz}$ has not been fully rejected. This can be resolved by shifting forwards the first transmission zero of the $5.8 \mathrm{GHz}$ filter. Although the essential results have been obtained in terms of spurious harmonics suppression, the return loss of the array at the two dominant resonant frequencies has decreased by about $7 \mathrm{~dB}$ each, i.e. resulting at about $23 \mathrm{~dB}$. This can be attributed to the extra metallization of the integrated filters and extra couplings involved in the new structure. The fabricated filtering array was measured using Agilent E8361A PNA Network Analyzer. The measured results have also been presented in Fig. 4. As seen, an excellent match between the simulation and measurement results has been obtained. The frequencies shift in the fabricated circuit is negligible. Furthermore, the measured Sparameters are substantially better than the simulated ones; with $35 \mathrm{~dB}$ at $2.4 \mathrm{GHz}$ and almost $30 \mathrm{~dB}$ at $5.8 \mathrm{GHz}$.

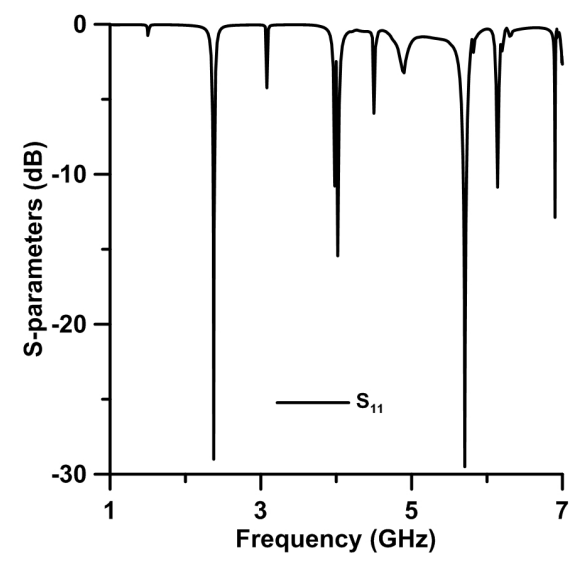

Fig. 2. S-parameters of standalone antenna array.

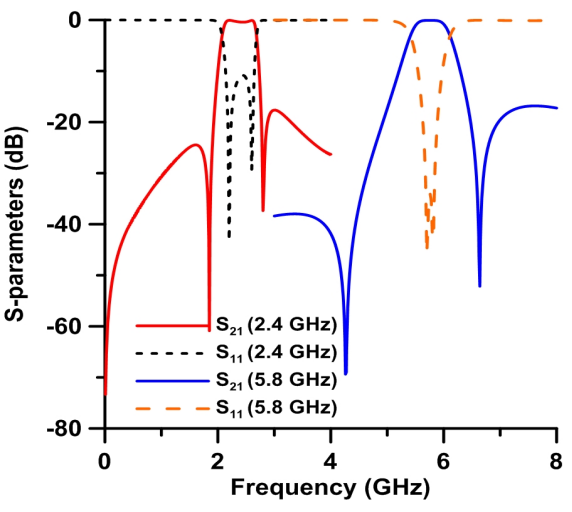

Fig. 3. S-parameters of standalone filters.

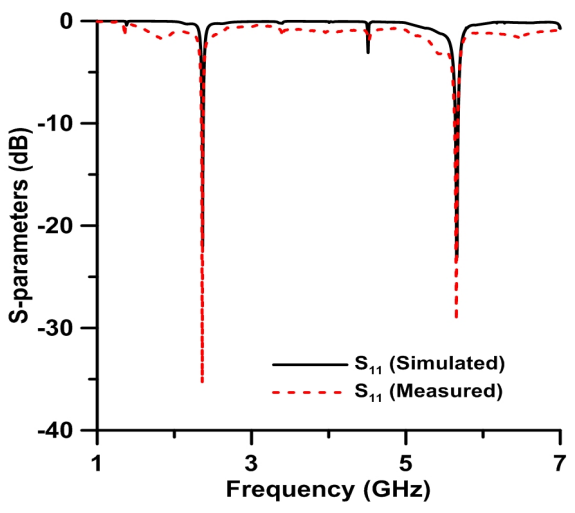

Fig. 4. S-parameters of antenna array with integrated filters.

\section{CONCLUSION}

A dual-band WLAN 1x2 antenna array, integrated with two pseudo-interdigital bandpass filters, is designed and presented. A standalone antenna array was simulated. It was found to have spurious harmonics in addition to the two main operational WLAN bands. The integrated filters are a means of rejecting the spurious harmonics while keeping the two fundamental frequencies intact. The filtering array was fabricated; and the simulation and measurement results shown. Full suppression of the spurious harmonics has been successfully achieved.

\section{REFERENCES}

[1] IEEE, "IEEE 802.11: Wireless LANs," 2013. [Online]. Available: http://standards.ieee.org/about/get/802/802.11.html

[2] W. K. Toh, X. Qing, and Z. Chen, "A planar dualband antenna array," IEEE Trans. on Ant. and Prop., vol. 59, no. 3, pp. 833-838, Mar. 2011.

[3] C. Lin and S. Chung, "A filtering microstrip antenna array," IEEE Trans. on Microwave Theory and Tech., vol. 59, no. 11, pp. 2856-2863, Nov. 2011.

[4] M. Rivera, J. Costantine, Tawk, and C. Christodoulou, "Failure detection and correction in switch reconfigurable antenna arrays," IEEE Antennas and Propagation Society International Symposium, pp. 976-979, 2011.

[5] S. Dasgupta, B. Gupta, and H. Saha, "Development of circular microstrip patch antenna array for rectenna application," IEEE India Conference INDICON, pp. 1-6, Dec. 2010. 